\title{
Anita Guerrini
}

The Courtiers' Anatomists: Animals and Humans in Louis XIV's Paris (Chicago:

University of Chicago Press, 2015), pp. 352, ills., \$35.00 (cloth), ISBN 978 o 226248832 .

Versailles occupies an important place in histories of Louis XIV's France. This is unsurprising given that it was the 'gilded cage' of the nobility, and home to a lavish court culture undergirding the power of the Sun King. Royal history features in Anita Guerrini's The Courtiers' Anatomists, but in unexpected ways. Rather than focusing on the deferential but self-interested courtier embedded in patronage networks, Guerrini develops the image of the courtiers' anatomists, the more humble state-sponsored men of science and letters who articulated new research programs. Specifically, she charts the emergence in Paris of a culture of anatomical inquiry reliant on the dissection of both human cadavers and living animals in order to arrive at new truths - and questions about the body.

These courtly anatomists relied on patronage both for a steady supply of dissection subjects and for spaces in which to conduct their work. The first chapter highlights their industry in acquiring human and animal bodies, the mainstay of their investigations. As the sites of anatomical dissection multiplied, so, too, did programs of inquiry. While the adoption of the Galenic teaching model and concomitant rejection of William Harvey's theory of blood circulation betrayed the Paris Faculty of Medicine's antiquated reputation, the newly formed King's Garden offered a fresh perspective. This was thanks to the outreach work undertaken by Joseph-Guichard Duverney, the talented showman and dexterous anatomist whose use of bodies as teaching tools eschewed the rote learning of the Faculty of Medicine. So was cemented the ritual of the staged dissection.

Duverney's reputation as a dissector-cum-lecturer spoke to the public and to sociable modes of eighteenth-century anatomy. But it was his second institutional home, the Paris Royal Academy of Sciences, where the courtiers' anatomists flourished. Against the backdrop of political intrigue - namely, the fall of Nicolas Fouquet and the subsequent rise of Louis XIV's favorite, Jean-Baptiste Colbert - Guerrini sets the scene for the early days of the Academy. Her account of Claude Perrault's pioneering efforts to make anatomy a serious preoccupation of the Academy alongside astronomy and chemistry gives new flourish to Alice Stroup's history of the nascent compagnie (Alice Stroup, A Company of Scientists: Botany, Patronage, and Community at the SeventeenthCentury Parisian Royal Academy of Sciences (Berkeley, CA, 1990)). In its spaces, a collective experimental enterprise was first realized, one built on consensus decision-making, authorial anonymity, and rigorous experimentalism. In re- 
turn for resources and the freedom to practice science, the Academy's savants honored the cult of the Sun King through their intellectual output.

The peak achievement of scientific and courtly ambition was the Histoire des animaux or History of animals project overseen by Perrault. It is the ultimate paper archive, providing evidence of the unique disciplinary foundations of seventeenth-century anatomy. Its history substantiates Guerrini's contention that anatomical investigation drew from the wellsprings of natural history and experimentalism. The project drew on the classificatory traditions of natural history dating back to Pliny, while exhibiting the experimental methods befitting of the new science through detailed descriptions and naturalistic engravings. In size and beauty, the engravings of the Histoire des animaux surpassed all previous efforts, thereby ennobling the image as a tool of the scientific method capable of enlisting yet more accurate dissections.

The dissection of exotic animals obtained from the Versailles menagerie became a cottage industry of the Academy. The Egyptian chameleon perfectly reflected the ambitions of charting new intellectual territory while building on the glory of Louis XIV's gift economy and regimes of diplomatic exchange. Equally, the dissection of rarities like ostriches, tortoises, monkeys, lions, beavers, and bears built bridges between the dirty, gruesome work of dissection and the sanitized image of Louis xIv's tamed natural world. Political image-making through animal symbolism was not new to the seventeenth century, but it was newly explored by the Sun King's propaganda machine. The appropriation of ancient animalia, medieval bestiaries, and New World exotica as royal and martial motifs evinced the impressive reach of Louis XIv's empire.

The Histoire des animaux project spanned several decades, thus accommodating changes in intellectual outlook. Its state-pensioned anatomists became deeply entwined with the royal universe while quietly asserting identities as individual practitioners. Most notably, the Academy adopted the seemingly unthinkable practice of crediting Perrault as the project's compiler, signaling a new landscape of credit. In this way, Guerrini's account points to - without fully articulating - the role of seventeenth-century anatomists in a longer history. They bridge Renaissance modes of courtly patronage with the commercial orientation of Enlightenment science. Their eclectic philosophical and disciplinary inspiration seemingly defied definition, and yet, a brand of inquiry emerged. Perrault's emphasis on both structure and function may have been a tacit if not deliberate aversion of Cartesian mechanism. Not that the mechanical philosophy was off the dissection table. Duverney described the African elephant's trunk as a system of pulleys and cords, while elsewhere in his experiments on animal digestion and respiration he shifted to the terrain of 'philosophical' explanation. 
The other elephant in Guerrini's book is the Scientific Revolution, a subject she deliberately sidesteps, not least because her subject is anatomy, rather than the physical sciences. Connections between the anatomical and astronomical sciences nonetheless figure in Guerrini's account, in the form of microscope-wielding, note-taking anatomists who rely on the communicative power of illustrations. The diligence of such anatomists is matched by Guerrini's own encyclopedic erudition. Her reader is convinced that dissection emerged as an integral pursuit of the new science. Anatomy consolidated a disciplinary status distinct from the medical professions, through a unique blend of experimentalism and natural history. Its success extended beyond courtly anatomists to the unsung artisans like André Colson, whose taxidermy and cabinet-making skills made him an invaluable assistant to Duverney (pp. 216-217). Guerrini's other actors are animals whose role as human standins speaks to a Galenic orthodoxy queried by Vesalius in what Andrew Cunningham has described as The Anatomical Renaissance (Andrew Cunningham, The Anatomical Renaissance: The Resurrection of the Anatomical Projects of the Ancients (Aldershot, 1997)). Guerrini's ambitions diverge from Cunningham's; her attentiveness to actors' categories undergirds a rich narrative in which the seventeenth-century dissector emerges as anatomist-physiologist.

The Courtiers' Anatomists is a welcome addition to the history of science and medicine, and to the history of the age of Louis XIV. The thesis that the Sun King exerted absolute control over intellectual output is debatable. What is not debatable, by contrast, is Guerrini's history of state-sponsored science, fleshed out in stimulating ways revelatory of both the interdisciplinary nature of seventeenth-century science and current scholarship in history of science. Guerrini adds a new twist to our understanding of the political culture of Old Regime France by enriching Sharon Kettering's classic conception of patronage, and by articulating a nuanced role for animals in the broader propaganda process outlined in Peter Burke's pioneering The Fabrication of Louis XIV (New Haven, CT and London, 1992). If the image of government functionaries providing noblemen with impolite anatomy lessons seems shocking, Guerrini artfully normalizes their work. The anatomist emerges as an integral part of court culture and the culture of the new sciences. While the Histoire des animaux was put on ice until its eighteenth-century resurrection, it served as an expression of royal power that flourished in seventeenth-century science, music, architecture, and literature.

\footnotetext{
Margaret Carlyle

University of Minnesota

mcarlyle@umn.edu
} 